\title{
YBX1 Indirectly Targets Heterochromatin-Repressed Inflammatory Response-Related Apoptosis Genes through Regulating CBX5 mRNA
}

\author{
Andreas Kloetgen ${ }^{1,2}, *$, Sujitha Duggimpudi ${ }^{2}$, Konstantin Schuschel ${ }^{3}{ }^{(D}$, Kebria Hezaveh $^{2,4}$, \\ Daniel Picard ${ }^{2}$, Heiner Schaal ${ }^{5}{ }^{\circ}$, Marc Remke ${ }^{2}$, Jan-Henning Klusmann ${ }^{3}{ }^{(1)}$, \\ Arndt Borkhardt ${ }^{2}{ }^{\oplus}$, Alice C. McHardy ${ }^{1}$ and Jessica I. Hoell ${ }^{2,3}$ \\ 1 Department of Computational Biology of Infection Research, Helmholtz Centre for Infection Research, \\ 38124 Braunschweig, Germany; alice.mchardy@helmholtz-hzi.de \\ 2 Department of Pediatric Oncology, Hematology and Clinical Immunology, Medical Faculty, \\ Heinrich-Heine-University, 40225 Düsseldorf, Germany; \\ sujitha.duggimpudi@med.uni-duesseldorf.de (S.D.); Kebria.Hezaveh@uhnresearch.ca (K.H.); \\ daniel.picard@med.uni-duesseldorf.de (D.P.); marc.remke@med.uni-duesseldorf.de (M.R.); \\ arndt.borkhardt@med.uni-duesseldorf.de (A.B.); jessica.hoell@uk-halle.de (J.I.H.) \\ 3 Department of Pediatrics 1, Martin Luther University Halle-Wittenberg, 06120 Halle, Germany; \\ konstantin.schuschel@uk-halle.de (K.S.); jan-henning.klusmann@uk-halle.de (J.-H.K.) \\ 4 Tumor Immunotherapy Program, Princess Margaret Cancer Centre, University Health Network, Toronto, \\ ON M5G 2C4, Canada \\ 5 Institute of Virology, Medical Faculty, Heinrich-Heine-University, 40225 Düsseldorf, Germany; \\ schaal@uni-duesseldorf.de \\ * Correspondence: andreas.kloetgen@helmholtz-hzi.de
}

Received: 2 June 2020; Accepted: 20 June 2020; Published: 23 June 2020

\begin{abstract}
Medulloblastomas arise from undifferentiated precursor cells in the cerebellum and account for about $20 \%$ of all solid brain tumors during childhood; standard therapies include radiation and chemotherapy, which oftentimes come with severe impairment of the cognitive development of the young patients. Here, we show that the posttranscriptional regulator Y-box binding protein 1 (YBX1), a DNA- and RNA-binding protein, acts as an oncogene in medulloblastomas by regulating cellular survival and apoptosis. We observed different cellular responses upon YBX1 knockdown in several medulloblastoma cell lines, with significantly altered transcription and subsequent apoptosis rates. Mechanistically, PAR-CLIP for YBX1 and integration with RNA-Seq data uncovered direct posttranscriptional control of the heterochromatin-associated gene $C B X 5$; upon YBX1 knockdown and subsequent CBX5 mRNA instability, heterochromatin-regulated genes involved in inflammatory response, apoptosis and death receptor signaling were de-repressed. Thus, YBX1 acts as an oncogene in medulloblastoma through indirect transcriptional regulation of inflammatory genes regulating apoptosis and represents a promising novel therapeutic target in this tumor entity.
\end{abstract}

Keywords: medulloblastoma; Y-box binding protein 1; PAR-CLIP; RNA-Seq; post-transcriptional gene regulation

\section{Introduction}

Medulloblastomas mainly arise from undifferentiated neural precursor cells within the cerebellum or dorsal brainstem [1] and account for around $20 \%$ of all malignant brain tumors in children [2-4]. Incidence rates estimated in children (1-14 years of age) and adults (15-30 years of age) show that children are about 4.4 times more likely to be diagnosed with medulloblastomas than adults [4]. 
Medulloblastomas are classified according to their molecular background into four subgroups [5]: Group 1, derived from granule neuron precursors in cerebellar external granule cell layer with aberrant Sonic hedgehog signaling (SHH) [6,7]; group 2, originated from dorsal brain stem progenitors and Wnt-signaling (Wnt) driven [8]; group 3 with association to Myc overexpression in diverse precursors [9-11]; and group 4, which is thought to arise from deep nuclei precursors in the upper rhombic lip [12]. Overall survival rates of children diagnosed with medulloblastoma increased within the past years to 70-80\% 5-year survival [13], but the outcome is dependent on the subgroups [14]. Standard therapies include radiation and adjuvant chemotherapy, which frequently result in severe side effects including impaired cognitive development especially in young patients and, thus, less invasive treatments and (ideally) targeted therapies are the focus of intense research $[15,16]$.

The Y-box binding protein 1 (YBX1) is a DNA- and RNA-binding protein containing a highly conserved cold-shock domain, which is involved in many different cellular processes such as cell proliferation and development [17]. This domain has already been structurally solved and has an affinity to 5-metylcytosine RNA [18]. The YBX1 RNA binding motif was not consistently reproduced by different studies in the past, however, it is considered to be C/A-rich [19-22]. YBX1 is an essential transcriptional and posttranscriptional regulator controlling cellular stress responses during embryonic development [23]. When highly expressed, YBX1 acts by multimerizing at mRNAs, both increasing mRNA stability while maintaining controlled translation [24,25]. It is further thought that specific binding of YBX1 to mRNAs at the $3^{\prime}$ UTR acts together with other proteins to stabilize the respective mRNAs [26-28]. Subsequently, binding of YBX1 on 3'UTR of mRNAs protects against exoribonuclease digestion, while 5'UTR binding inhibits the rate of translation by interfering with eIF4E binding [29]. Interestingly, reports have shown that $\mathrm{YBX} 1$ is highly expressed in different cancers, such as breast cancer, glioblastomas or myelomas [30-32]. Knockdown of YBX1 in glioblastoma cell lines had pronounced effects on cell survival and knockdown of YBX1 in mice led to a reduced tumor size [33,34].

We here show that YBX1 can also be considered as an oncogene in medulloblastomas and leads to decreased survival of various medulloblastoma cell lines upon knockdown. More specifically, we identified (through differential gene expression analysis) essential signaling pathways related to inflammation and apoptosis, which are altered in the medulloblastoma cell line UW228-3. By performing transcriptome-wide RNA binding analyses, we found that YBX1 binds mostly the 3' UTR regions of genes, suggesting direct involvement in posttranscriptional gene regulation, including the key heterochromatin-associated protein CBX5. CBX5 in turn is a gene silencer strongly associating with methylated H3K9 lysines, a mark for heterochromatin. Subsequently, inhibition of YBX1 indirectly leads to broad upregulation of heterochromatin repressed genes including those controlling inflammatory response genes and apoptosis signaling, ultimately leading to cell death. This renders YBX1 or its target CBX5 interesting therapeutic targets in many malignancies.

\section{Results}

\subsection{YBX1 Is an Essential RBP for Cell Survival in Medulloblastomas}

We reanalyzed microarray expression data of samples from 64 medulloblastoma patients to analyze RNA-binding proteins (RBPs) expression in patients across the four reported sub-groups [35]. Among a list of 1220 canonical RBPs represented on the microarray [36], we found that YBX1 is ubiquitously expressed in medulloblastoma patient samples across all sub-types and ranks among the top expressed RBPs on average (Figure 1a). However, there was no clustering of the medulloblastoma subgroups $\mathrm{SHH}, \mathrm{WNT}$, group 3 and group 4 based on YBX1 expression. Furthermore, to identify its role in the maintenance of cellular survival, we queried the DepMap database (https://depmap.org). This database holds information on gene essentiality (based on cell survival) across a broad spectrum of cell lines represented by the CERES score, deriving its information from genome-wide CRISPR-Cas9 library screens [37]. A lower negative CERES score determines slower cell growth or increased cell death upon knockout of the respective gene, thus rendering the respective gene as essential for cellular 
growth and survival. We considered all eight available medulloblastoma cell lines and found that YBX1 is among the top 20-30\% quantile of essential genes among 1621 canonical RBPs targeted in the screen (Figure 1b). To confirm its essentiality in medulloblastomas, we used an siRNA pool of 30 siRNAs targeting YBX1 for the knockdown (KD) of YBX1 in medulloblastoma cell lines DAOY [38], Med8A (RRID: CVCL_M137) and UW228-3 [39]. We were able to validate the DepMap findings upon targeting YBX1 in UW228-3 but neither in DAOY nor in Med8A (Figure 1c, A1a). We confirmed that YBX1 was sufficiently targeted by the siRNA pool on both mRNA and protein levels in all three cell lines (Figure A1b-d). These results imply that $\mathrm{YBX} 1$ as a potential candidate for therapeutic targeting in medulloblastoma.

a

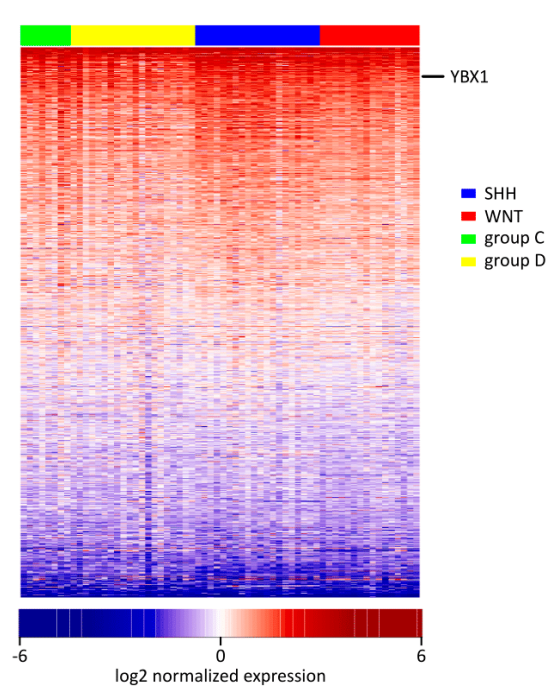

b

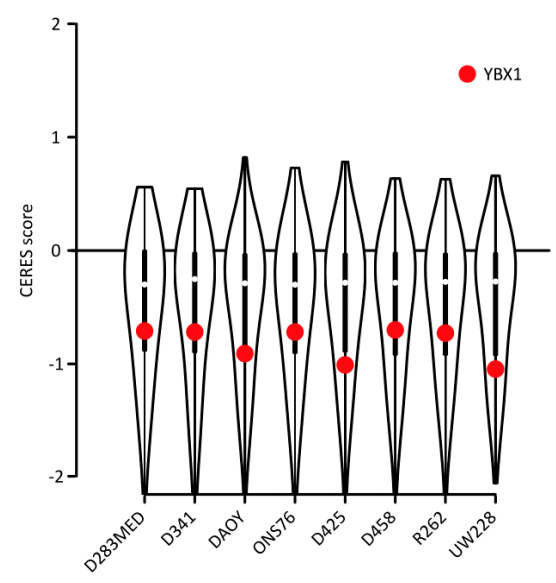

c
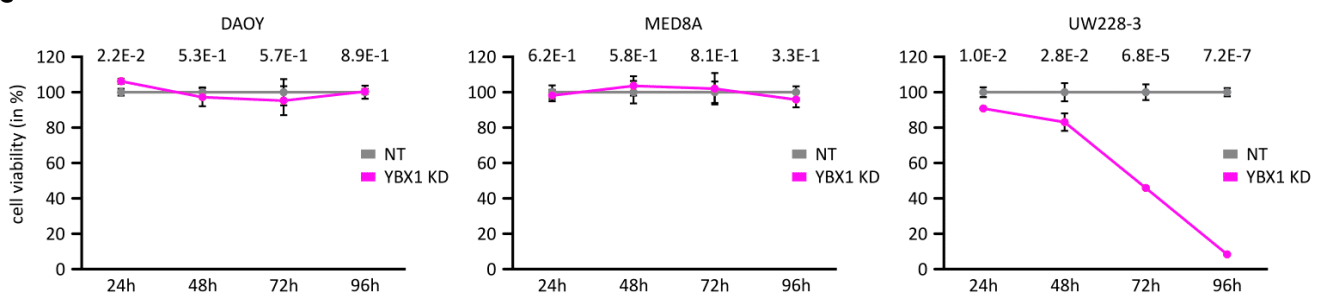

Figure 1. YBX1 is essential for cellular survival in medulloblastoma patients and cell lines. (a) Heatmap representation of a set of expression of 1220 RNA-binding proteins across medulloblastoma patients out of a total of $1827 \mathrm{RBPs}$ (the remainder of RBPs was not present on the microarrays). Rows are sorted by average expression across all patients, and $\log 2$ normalized expression value is shown. (b) CERES score representing the essentiality of genes for survival of 483 RNA-binding proteins as in a), downloaded from DepMap for a total of eight medulloblastoma cell lines. YBX1 CERES score is highlighted. (c) Cell viability assay showing survival for three medulloblastoma cell lines upon YBX1 knockdown (KD) measured at different time points (YBX1 siRNA-mediated knockdown compared to control; each time point was normalized against its respective control sample).

\subsection{YBX1 Controls Inflammatory Response and Apoptosis Genes}

We made use of our siRNA pool targeting YBX1 to perform RNA-seq before and after knockdown (KD) of YBX1 to identify its transcriptomic impact. We performed differential gene expression analysis in each cell line between negative control (NT) and YBX1 KD samples. Upon YBX1 KD, we found only 40 differentially expressed genes in DAOY, 92 DE genes in Med8A but 1,662 DE genes in UW228-3 (Figure 2a; FDR $\leq 0.05$ and $\log 2 \mathrm{FC}>1 / \log 2 \mathrm{FC}<-1$ ). Since there were only minor effects on cell survival and gene expression in DAOY and Med8A, we were interested to what degree the few differentially expressed genes in DAOY and Med8A were affected in the highly responsive UW228-3 cell line. Out of 
the significantly upregulated genes in DAOY and Med8A, a high number of genes overlapped with those significantly upregulated in UW228-3 upon YBX1 KD (Figure 2b,c). The genes upregulated in all three cell lines are involved in inflammatory responses, such as IFNL1, CXCL10, CXCL11 or USP18.

a

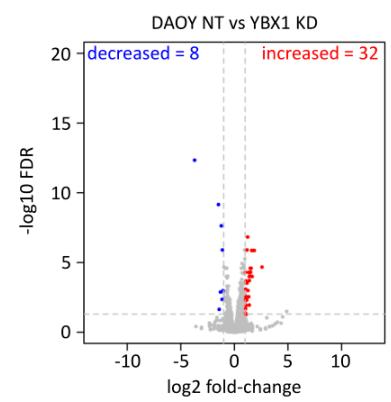

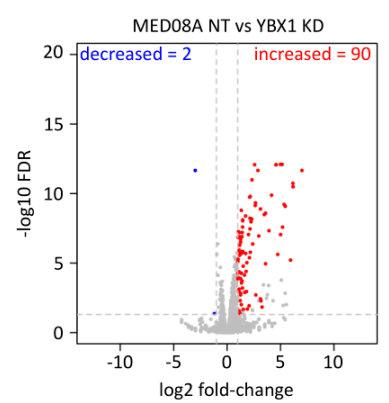

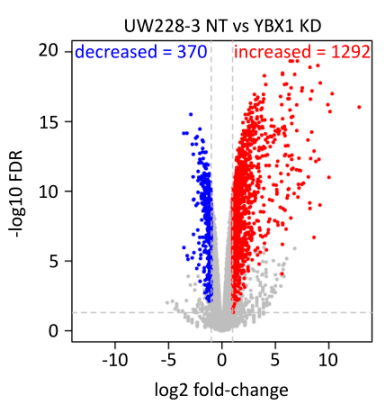

b

down-regulated in YBX1 KD
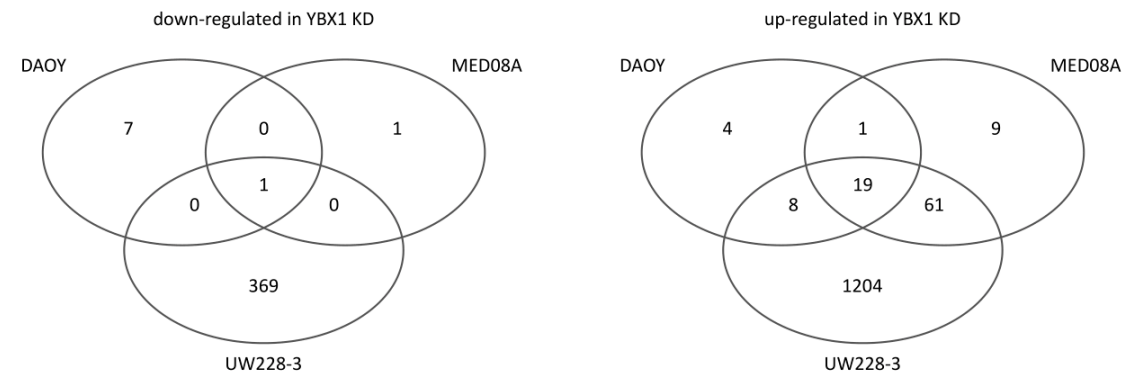

c

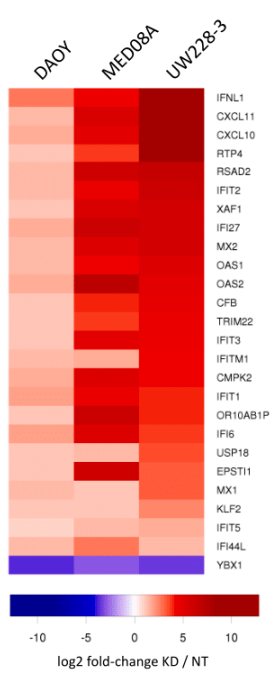

d

Neuroinflammation Signaling Pathway Tec Kinase Signaling Death Receptor Signaling

Interferon Signaling

Retinoic acid mediated apoptosis signaling

NF-kB signaling

PD-1/PD-L1 cancer immunotherapy pathway

PPAR Signaling

PPARalpha/RXRalpha actication
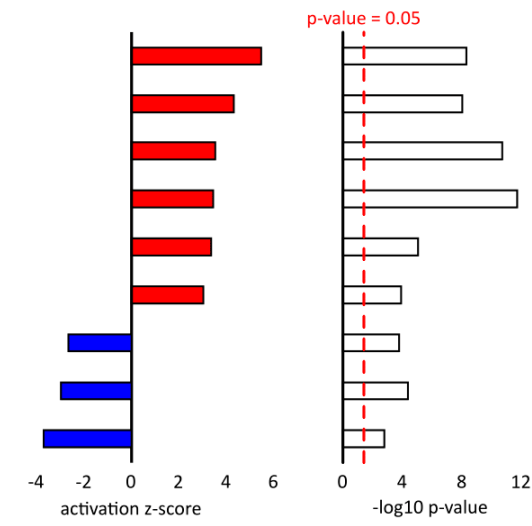

Figure 2. YBX1 knockdown globally induces inflammatory signaling cascades leading to apoptosis. (a) Volcano plot representations of differentially expressed genes in three medulloblastoma cell lines upon YBX1 KD. Differentially expressed genes are highlighted (FDR $<0.05 ; \log 2 \mathrm{FC}>1$ or $\log 2 \mathrm{FC}<-1$ ). (b) Venn diagrams for the overlap of differentially expressed genes across the three cell lines as highlighted in a). (c) Differential expression of commonly deregulated genes across all three cell lines as depicted in b). Heatmap shows the log2 fold-change in each cell line between YBX1 KD and NT control. (d) Ingenuity Pathway Analysis (IPA) was performed on all differentially expressed genes in UW228-3 as highlighted in a). Bar plots represent activation z-score and -log10 $p$-value upon YBX1 KD of the canonical pathway analysis of IPA.

Lastly, we were interested in potential pathways deregulated upon YBX1 KD, and whether these are shared across all three cell lines despite their variable expressional and survival responses. We performed a pathway analysis using Ingenuity Pathway Analysis (IPA) and confirmed that 
the reported differentially expressed genes in UW228-3 are related to apoptosis, with "death receptor signaling" being among the most significantly affected pathways (activation z-score $=3.528$, $p$-value $=2.2 \times 10^{-11}$ ) followed by "retinoic acid mediated apoptosis" (activation z-score $=3.357$, $p$-value $\left.=9.2 \times 10^{-6}\right)$ (Figure 2d). Interestingly, inflammation pathways such as "interferon signaling" (activation z-score $=3.441, p$-value $=1.8 \times 10^{-12}$ ) and "neuroinflammation signaling" (activation z-score $=5.461, p$-value $=5.1 \times 10^{-9}$ ) were also found among the top pathways (Figure $2 \mathrm{~d}$ ). The latter describes the process of how microglia control homeostasis in the central nervous system which generally serves a neuroprotective role and is described by expression of pro-inflammatory cytokines [40]. Individual upregulated genes upon YBX1 KD associated with this pathway include several apoptosis-related inflammatory genes such as FAS, TNF, several caspases (e.g., CASP8) and MHC class I genes.

We then sought to compare the pathway analyses across all cell lines and found that similar pathways were deregulated in DAOY and Med8A despite their modest transcriptional changes upon YBX1 KD. These were reflected in "interferon signaling" being activated in both DAOY and Med8A (Figure A2a), confirming a trend of inflammation-related genes to be equally upregulated across all three cell lines (Figure 2c, Figure A2b). Additionally, Med8A also displayed other significantly activated pathways, including "retinoic acid mediated apoptosis" as well as "neuroinflammation signaling" (Figure A2c). These results highlight the unique mechanism of YBX1 in apoptosis control via inflammatory signaling genes, but also underlines how complex the transcriptional and posttranscriptional control is across different cell lines.

\subsection{YBX1 Targets 3'UTRs and Indirectly Regulates Heterochromatin-Repressed Apoptosis-Related Inflammatory Response Genes}

In order to define direct targets from our transcriptome analysis, we performed PAR-CLIP for YBX1 to reveal its in vitro RNA-binding pattern. We found 2054 binding sites in 1476 distinct genes. Most of the binding sites were within $3^{\prime}$ UTRs and exons of the targeted genes (Figure 3a), as was previously reported [19-22]. The most significant binding motif for YBX1 using MEME across all $3^{\prime}$ UTR and exon binding sites found a rather non-specific C/A rich binding pattern, which is in line with earlier findings (Figure $3 \mathrm{~b}$ ). The exact role of YBX1 in posttranscriptional control and translation varies highly among studied systems, and it further depends on a YBX1/mRNA ratio in each cell (see [29] and references therein). Since the previously reported posttranscriptional regulation of fully mature mRNAs mediated by YBX1 happens within the cytoplasm, we checked for cellular localization of YBX1 in DAOY and UW228-3. We found that YBX1 localizes primarily within the cytoplasm (Figure A3a; $72 \%$ cytoplasmic; GAPDH $85 \%$ cytoplasmic), thus indicating a potential role in mRNA stability and translation. To elucidate a potential effect of YBX1 in mRNA stability control, we were specifically interested to what degree $3^{\prime} \mathrm{UTR}$ binding of genes directly affects their expression upon knockdown of YBX1. We found that downregulated genes were only enriched in $3^{\prime}$ UTR binding of YBX1 to a small degree, suggesting that these genes might have been stabilized and protected by expressed YBX1 and their mRNAs are degraded upon YBX1 KD. What was more striking though was the fact that upregulated genes upon YBX1 KD were specifically depleted of YBX1 binding, suggesting an indirect downstream effect of the knockdown increasing the expression of a vast number of genes (Figure 3c). We thus performed IPA upstream regulator analysis to identify potential genes that were responsible for the strong expressional upregulation upon YBX1 KD, which might be directly targeted by YBX1 itself. Indeed, we found that five genes were simultaneously predicted to be inhibited based on their downstream targets and were themselves downregulated in their expression (Figure 3d). Only one out of the five was also bound by YBX1 in its $3^{\prime}$ UTR in our PAR-CLIP data, which was CBX5 (Figure 3d,e). We also confirmed quantitative expression loss in UW228-3 with our RNA-seq (Figure A3b). We validated that the majority of known CBX5 target genes from the upstream regulator analysis were indeed upregulated upon reduced expression of CBX5 due to YBX1 KD (Figure 3f). CBX5, also called heterochromatin protein 1 alpha (HP1-alpha), is a DNA-binding protein that associates with heterochromatin mark Histone $3 \mathrm{~K} 9$ trimethylation (H3K9me3), and to some extent with $\mathrm{H} 3 \mathrm{~K} 9$ mono- 
and dimethylation [41,42]. It is thus an important factor in heterochromatin related gene repression, while it does not maintain histone methylation or the heterochromatin compaction but rather acts as a co-factor for transcription repression. This led us to consider specific histone modification H3K9me3 demarcating heterochromatin and CBX5 binding throughout the gene bodies and promoters of differentially expressed genes upon YBX1 KD.

a

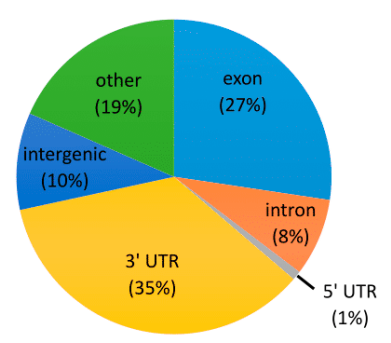

C

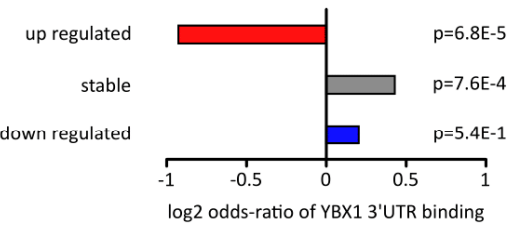

e

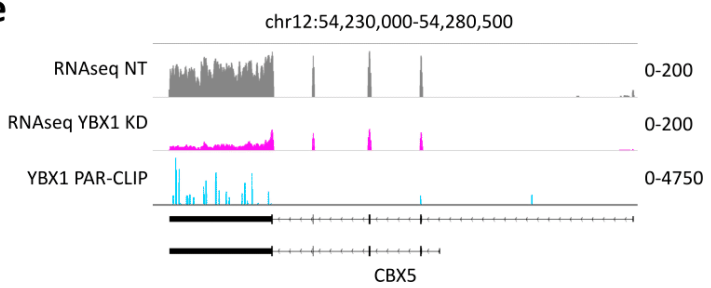

g
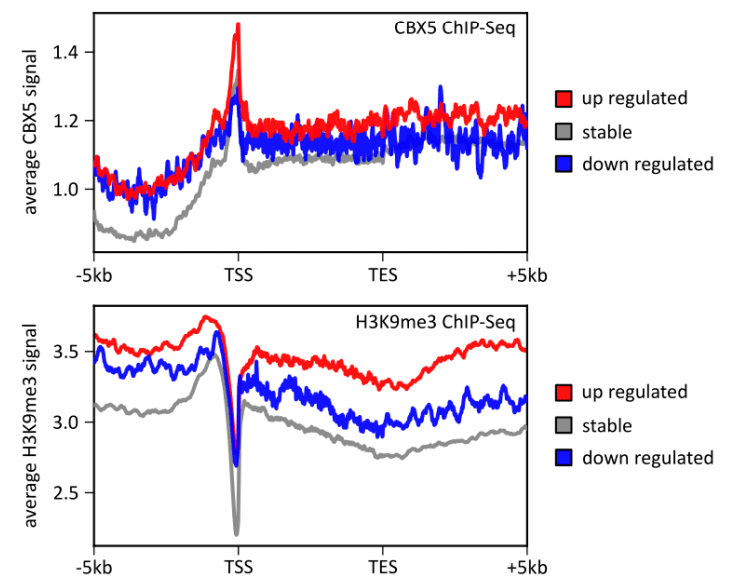

b

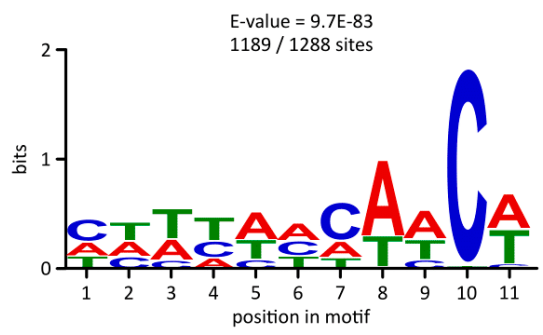

d

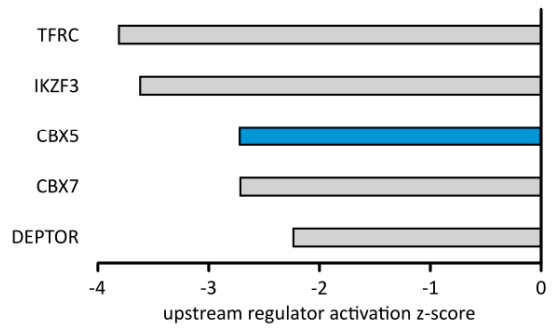

$f$

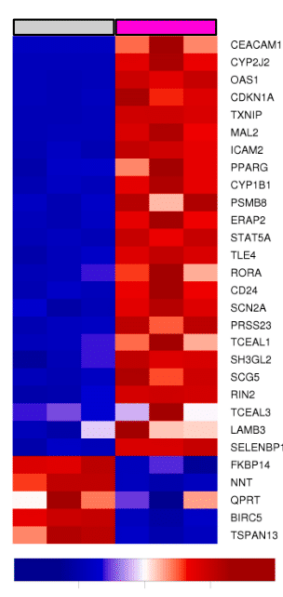

0
Row Z-Score

Figure 3. $\mathrm{YBX} 1$ binding to $\mathrm{CBX} 5 \mathrm{mRNA}$ indirectly affects repression of inflammatory pathway genes. (a) YBX1 PAR-CLIP performed in HEK293 cells reveals binding pattern of YBX1 using all Bmix detected binding sites within gene annotations. Annotation was performed with homer annotatePeaks.pl. (b) Motif analysis of YBX1 binding sites within 3'UTRs and exons (1288 total binding sites) was performed with the MEME suite, and the most significant motif is shown. (c) Enrichment analysis of 3'UTR/exon binding of YBX1 within differentially regulated genes in UW228-3 upon YBX1 KD. Enrichment was performed in R using Fisher's exact test (fisher.test), and $\log 2$ odds ratio and $p$-value 
are reported. (d) IPA upstream regulator analysis was performed with all differentially expressed genes in UW228-3. Only genes with an activation z-score of $<-1.96$, expression log2 fold-change $<-1.0$ and expression FDR $<0.05$ are shown. Blue highlight further depicts genes with 3'UTR/exon binding of YBX1 defined by YBX1 PAR-CLIP. (e) Tracks represent RNA-Seq of UW228-3 (normalized FPKM reads) and PAR-CLIP of YBX1 (normalized CPM reads) around the CBX5 gene. Tracks were created with IGV. (f) Heatmap of all known downstream targets of CBX5 as reported by IPA upstream regulator analysis. (g) ChIP-Seq signal of CBX5 binding in GM12878 cells (upper) and H3K9me3 in A549 cells (lower) within and $+/-5 \mathrm{~kb}$ around genes reported to be differentially expressed in UW228-3. Average signal across all regions per category was created with DeepTools.

We found that specifically genes upregulated upon YBX1 KD have both the strongest coverage of H3K9me3 and CBX5, while stable and downregulated genes upon YBX1 KD have overall weaker H3K9me3 and CBX5 signal within gene bodies and at respective promoters (Figure 3g). These results suggest an indirect role of $\mathrm{YBX} 1$ as an oncogene signaling via histone modification associated gene $C B X 5$ to indirectly control transcriptional regulation of hundreds of genes. As these genes appear to be associated with an inflammatory response, this enables YBX1 to indirectly repress inflammatory response and apoptosis in medulloblastoma.

\section{Discussion}

RBPs have been found to be crucial players in posttranscriptional gene regulation in almost all kinds of tumors. We here analyzed the oncogenic effect of YBX1 in three medulloblastoma cell lines based on RNA-Seq and PAR-CLIP data, revealing important insights into its posttranscriptional functions and its potential target gene network. The high expression and essentiality of YBX1 in the tested cell lines as well as its high expression levels in medulloblastoma patients supports the hypothesis, that YBX1 also plays an important role in cell survival in medulloblastomas and likely also in this cancer acts as an oncogene as was reported for other cancers [43-45].

In exploring a broader pattern across the differentially expressed genes upon YBX1 KD, we found several pathways associated with inflammatory response and apoptosis signaling related to retinoic acid induced apoptosis to be activated following YBX1 KD. Several studies already showed that retinoic acid induced cell growth arrest and apoptosis is a suitable anti-tumor effect in medulloblastoma [46,47], but many cell lines including DAOY and UW228 are considered to be resistant against RA induced cell death $[48,49]$. Yet, different mechanisms through which retinoic acid induces apoptosis in medulloblastoma were reported, including expression of BMP2 [48] or expression of FAS and its ligand FASL [50]. Other pathways were specifically associated with (neuro-)inflammation related apoptosis. A recent report showed that YBX1 supports immune evasion in hepatocellular carcinoma cells by decreasing the release of important inflammatory cytokines such as IL10 and TGF $\beta$ [51], further underlining our findings of a negative regulation of apoptosis-related cytokines and chemokines in medulloblastoma. Importantly, despite less pronounced transcriptional effects in the other cell lines, we found similar pathways to be significantly enriched upon YBX1 KD in DAOY and Med8A. However, it is possible that other mechanisms render these cells either more resistant to YBX1 KD, or that experimental timing has had an impact on our results. On the one hand, the genome-wide CRISPR screen downloaded from the DepMap data, which included information for cell lines DAOY and UW228, compared knockdown at day 21 post transfection of gRNAs versus day 7 (i.e., 14 days difference to control time point), while our in vitro experiments have been conducted only 1-4 days post YBX1 KD. On the other hand, Med8A is derived from a group 3 medulloblastoma with MYC amplification and TP53 WT status [52]. It also expresses CBX5 at low levels (Figure A3b). In comparison, both DAOY and UW228-3 are SHH medulloblastomas with TP53 loss [52] and higher CBX5 expression. Thus, we suggest that Med8A with highly different molecular properties compared to UW228-3 is resistant to the changes upon YBX1 KD. To elucidate potential differences between responses in DAOY and UW228-3, we also found that IPA canonical pathway "neuroinflammation signaling" was inhibited in WT UW228-3 compared to WT DAOY (activation z-score $=-2.48$; $p$-value $8.3 \times 10^{-6}$ ), 
however, the differentially expressed genes between WT DAOY and WT UW228-3 that are part of the pathway mostly included inflammatory cytokines such as CCL2, TLR4 and TLR5 upregulated in DAOY. This suggests that DAOY underlies a pathological neuroinflammation and might be less susceptible to YBX1 KD mediated apoptosis. This analysis also predicted CBX5 to be activated in WT UW228-3 compared to WT DAOY (activation z-score $=3.0 ; p$-value $5.6 \times 10^{-9}$ ), thus rendering UW228-3 more susceptible to a healthy brain-damage response and apoptosis induced by YBX1 KD signaling via CBX5.

We also set out to define the direct impacts of YBX1 KD in medulloblastoma on posttranscriptional control. PAR-CLIP data revealed mainly targets in $3^{\prime}$ UTR and exons which is in line with previous publications and the known functions of YBX1 regulating translational control and mRNA stability [21]. However, this does not explain the vast upregulation of many genes in UW228-3 upon YBX1 KD, which led us to consider this to be an indirect effect. We found strong recurrent binding throughout the $3^{\prime}$ UTR of CBX5. The natural targets of CBX5 are repressed when CBX5 is expressed due to its association with repressive histone modification $\mathrm{H} 3 \mathrm{~K} 9 \mathrm{me}$. An inflammatory gene set has been described before to be under the regulation of CBX5 [53], which becomes actively transcribed upon YBX1 KD due to degradation of then unprotected CBX5 mRNA. Because other genes than CBX5 directly bound by YBX1 and differentially expressed upon $\mathrm{YBX} 1 \mathrm{KD}$ are involved in inflammatory response and apoptosis based on Gene Ontology annotations, such as NFE2L1 and PSMA6, we cannot rule out that CBX5 is not the sole driver of the cellular responses to YBX1 KD but may be accompanied by additional apoptosis driving factors.

Further evidence is given by TNF $\alpha$ mediated inflammation, upon which rapid removal of repressive histone marks $\mathrm{H} 3 \mathrm{~K} 9 \mathrm{me} 2 / \mathrm{me} 3$ and $\mathrm{H} 3 \mathrm{~K} 27 \mathrm{me} 3$ leads to activation of Nf-kB and other inflammatory signaling cascades via KDM7A and UTX [54]. This is in line with our hypothesis of gene induction of heterochromatin repressed inflammatory signaling genes.

Lastly, in view of the urgent need for targeted therapies, and since YBX1 resistance-suppressing therapeutic effects have been already reported [45], this RBP represents a promising candidate for targeted therapy. Initial attempts to identify low-molecular inhibitors that compete with RNA binding have already been carried out. For instance, fisetin (a phenolic fruit/vegetable compound) was predicted to compete with RNA at the cold shock domain of YBX1, inhibiting in vitro and in vivo tumor growth of prostate cancer [55]. Therefore, it appears essential to unravel even further targetable structures related to proteins (in-)directly controlling inflammation and apoptosis in medulloblastoma.

\section{Materials and Methods}

\subsection{Cell Lines}

Cells were maintained in DMEM (Sigma-Aldrich, St. Louis, MO, USA) including $10 \%$ fetal calf serum (Invitrogen Gibco, Carlsbad, CA, USA), 1\% non-essential amino acids (Gibco), 1\% penicillin/streptomycin (Gibco) and $1 \%$ sodium pyruvate (Gibco) at $37{ }^{\circ} \mathrm{C}$ and $5 \% \mathrm{CO}_{2}$ in $175 \mathrm{~cm}^{2}$ flasks. For maintenance of cell confluency, the cells were washed with phosphate buffered saline (Lonza) and detached from the flask surface using trypsin/EDTA solution (Biochrom GmbH, Berlin, Germany). For knockdown cells were seeded $24 \mathrm{~h}$ prior siRNA transfection at $60 \%$ confluency.

\section{2. $q R T-P C R$}

Total RNA was extracted using the RNeasy Mini kit (Qiagen, Venlo, Netherlands) and cDNA was synthesized using Superscript Reverse Transcriptase Kit III (Invitrogen, Carlsbad, CA, USA). qRT-PCR was performed using Power SYBR green kit (Applied Biosystems, Foster City, CA, USA). All reactions were run on an ABI 7500 real time PCR machine (Applied Biosystems) as a biological triplicate (TaqMan Assay, Hs00358903_g1, catalog number 4351372, ThermoFisher Scientific, Waltham, MA, USA). Data was acquired using the ABI SDS 2.0.1 software package. The obtained CT values were normalized per tested gene with the respective beta actin expression. 


\subsection{Western Blot and Protein Localization}

The cells were washed using phosphate buffered saline (PBS, Lonza, Basel, Switzerland). After gentle rocking PBS was discarded and cells were detached by incubating with Trypsin/EDTA Solution (Biochrom) at $37^{\circ} \mathrm{C}$ for $5 \mathrm{~min}$ and dislodged using a scraper. The mixtures were pipetted into microcentrifuge tubes and centrifuged at $450 \times g 5$ for minutes. The supernatant was discarded and the cells were washed with PBS, followed by centrifugation at $450 \times g$ at $5 \mathrm{~min}$. After removal of the supernatant the pellet was dissolved in RIPA-buffer (Sigma-Aldrich) and boiled at $95{ }^{\circ} \mathrm{C}$ for $10 \mathrm{~min}$. The protein concentration was determined using the Pierce BCA Protein-Assay (ThermoFisher Scientific). Protein extracts were resolved on a $10 \%$ polyacrylamide gel, electroblotted to nitrocellulose membranes. The membranes were blocked with 5\% milk solved in TBST (Sigma-Aldrich) for unspecific binding and incubated with 1:2000 diluted monoclonal rabbit anti-YBX1 (D2A11, Cell Signaling Technology, Danvers, MA, USA) at $4{ }^{\circ} \mathrm{C}$ for $24 \mathrm{~h}$. The membranes were washed with TBST and incubated with 1:1000 diluted monoclonal HRP-linked anti-rabbit or anti-mouse (\#7074; \#7076, Cell Signaling Technology) at room temperature for $1 \mathrm{~h}$, followed by an additional washing step. The membranes were analyzed using ChemiDoc (Bio-Rad, Hercules, CA, USA) and LumiGLO (Cell Signaling Technology).

For protein localization, NE-PER Nuclear and Cytoplasmic Extraction Reagents (Thermo Scientific) were used to prepare cytoplasmic and nuclear extracts. The adherent cells were harvested with Trypsin/EDTA-solution (Biochrom) and centrifuged at $450 \times g$ for $5 \mathrm{~min}$. The pellet were washed with PBS, transferred into a microcentrifuge tube and centrifuged at $450 \times g$ for $5 \mathrm{~min}$. The supernatant was removed and ice-cold CER I added to the pellet. The tube was incubated at $4{ }^{\circ} \mathrm{C}$ for $15 \mathrm{~min}$ and vortexed periodically. The mixture was supplemented with CER II, vortexed and incubated at $4{ }^{\circ} \mathrm{C}$ for one minute. After an additional centrifugation step at $16,000 \times g$ for $5 \mathrm{~min}$, the supernatant (cytoplasmic fraction) was transferred into a clean microcentrifuge tube and stored at $-20^{\circ} \mathrm{C}$. Ice-cold NER was added to the pellet and the tube was incubated at $4{ }^{\circ} \mathrm{C}$ for $40 \mathrm{~min}$, interrupted by periodic vortexing. The tube was centrifuged at $16,000 \times g$ for $10 \mathrm{~min}$, the supernatant was collected and stored at $-20^{\circ} \mathrm{C}$. For protein localization analysis, the membranes were incubated with the corresponding antibodies, monoclonal rabbit anti-PARP (\#9532, Cell Signaling Technology) and monoclonal mouse anti-GAPDH (Cell Signaling Technology; \#97166). The amount of YBX1 and GAPDH in the fractions was determined by quantifying the bands on the membrane using ImageJ version 1.53a [56] and the macro "Band/Peak Quantification Tool", following the respective protocol (dx.doi.org/10.17504/ protocols.io.7vghn3w). Cytoplasmic localization was calculated by dividing the cytoplasmic fraction by the sum of cytoplasmic and nuclear fraction.

\section{4. siRNA-Mediated Knockdown}

SiRNA transfections (50 nM final concentration; duration of knockdown 24-96 h; siRNA pools obtained from siTOOLs Biotech GmbH, Planegg, Germany) of DAOY, Med8A and UW228-3 cells were performed in 24-well format using Lipofectamine RNAiMAX (Invitrogen) as described by the manufacturer. Total RNA was extracted using TRIzol (Invitrogen) and further purified using the RNeasy purification kit (Qiagen). The use of a pool of siRNAs reduces off-target effects and improves on-target specificity [57].

\subsection{Cell Viability Assay}

We have performed cell proliferation assays using the CCK-8 kit (Sigma-Aldrich) as per manufacturer's guidelines. Cells were either transfected with siRNAs targeting YBX1 or non-targeting controls as described above and subsequently seeded into 96 well plates. After addition of $10 \mu \mathrm{L}$ of CCK-8 per well with $1 \times 10^{5}$ cells, light absorbance at $450 \mathrm{~nm}$ was measured using a Tecan Photometer (Maennedorf, Switzerland). 


\subsection{RNA-Seq}

cDNA libraries for subsequent sequencing were prepared according to the manufacturer's instructions using TruSeq Total RNA sample preparation kit (Illumina) and further sequenced using Illumina HiSeq 2500 (single read, 100 cycles).

\subsection{PAR-CLIP}

PAR-CLIP from T-REx HEK293 Flp-In cells (Invitrogen) stably overexpressing FLAG/HA-tagged YBX1 was performed as described previously [58]. Briefly, cells were grown in medium supplemented with $100 \mu \mathrm{M} 4 \mathrm{SU}$ for $12 \mathrm{~h}$ prior to crosslinking. After decantation of the medium, the cells were washed in PBS followed by irradiation with 0.15 J per $\mathrm{cm} 2$ total energy of $365 \mathrm{~nm}$ UV light. Cells were then harvested, lysed and the cleared lysate was treated with RNase T1. Flag-HA tagged YBX1 was immunoprecipitated with an anti-FLAG M2 monoclonal antibody (Sigma) conjugated to dynabeads (Invitrogen). After a subsequent second RNase T1 digestion, beads were washed in IP wash buffer, then resuspended in dephosphorylation buffer, and lastly incubated with calf intestinal alkaline phosphatase beads. The crosslinked RNA was then radiolabelled with T4 PN kinase andwashed. Release of the protein-RNA complex from the beads was achieved by incubating the complex at $90^{\circ} \mathrm{C}$ and separating on an SDS gel. The protein-RNA complex based on the size (approximately between 18 and 28 bases) was excised from the gel followed by proteinase K digestion. The remaining RNA was precipitated with phenol-chloroform extraction and ethanol precipitation. Then, standard cDNA library preparation of the 5'-32P-phosphorylated RNA was performed as follows. RNA was ligated to adapters at 3'and $5^{\prime}$ ends followed by reverse transcription. The resulting cDNA was amplified by adapter specific primers and subjected to Illumina sequencing with an Illumina HiSeq 2500 (single end, 50 cycles).

\subsection{Bioinformatics}

\subsubsection{RNA-Seq}

We obtained a total of 514,012,225 sequencing reads for RNA-Seq of all three cell lines prior to and after YBX1 KD. Reads were aligned with the STAR aligner [59] (version 2.7.3a; specific parameters —outFilterMismatchNoverLmax 0.05; -outFilterMultimapNmax 1) against the human reference genome GRCh38. Read counts were calculated with the STAR aligner inherent method (-quantMode GeneCounts) using gene annotations downloaded from Ensembl Genes V82. A total of 313,137,305 reads $(60.92 \%)$ could be mapped to annotated genes. The obtained read counts were normalized for sequencing depth per sample and gene length by edgeR [60] (version 3.16.5) function rpkm. Differential gene expression analysis was performed using edgeR functions glmQLFit and glmQLFTest between NT and YBX1 KD in each cell line independently and results were subsequently corrected for multiple testing using the false discovery rate (FDR).

\subsubsection{Pathway Analysis}

Pathway analysis and Upstream Regulator Analysis was performed using QIAGEN's Ingenuity ${ }^{\circledR}$ Pathway Analysis (IPA ${ }^{\circledR}$, QIAGEN Redwood City, www.qiagen.com/ingenuity). We selected genes as differentially expressed for the purpose of the analysis if FDR $<0.05$ and $\log 2 \mathrm{FC}>1.0$ or $\log 2 \mathrm{FC}<-1.0$ between NT and YBX1 KD for all three cell lines.

\subsubsection{PAR-CLIP}

We obtained a total of $136,094,488$ PAR-CLIP sequencing reads. First, adapter sequences and low-quality ends were trimmed using cutadapt [61] (version 1.4.1), keeping all reads longer than 16 bases for downstream analyses. All remaining reads were aligned against GRCh38 and a transcriptome databases downloaded from Ensembl Genes V82 with the PARA-suite pipeline [62]. All 2,839,752 aligned reads were stacked into clusters with BMix in a stranded fashion (default parameters). 
This resulted in a total 2054 detected binding sites for YBX1 in 1476 distinct genes using homer [63] (annotatePeaks.pl function version 4.11) with hg38 annotations. We have used all binding sites falling within $3^{\prime}$ UTRs or exons (1288 total binding sites) to conduct a motif analysis with the MEME suite [64] (parameters: zoops mode; minimum width $=8$; maximum width $=20$; search given strand only), and reported the top scoring motif.

\subsubsection{ChIP-Seq Data Integration}

We downloaded pre-processed bigwig files for ChIP-Seq data for H3K9me3 (in A549 cells; accession ENCSR775TAI) and for CBX5 (in GM12878 cells; accession ENCSR372GIN) from ENCODE [65]. Non-canonical chromosome data was removed from bigwig files. Average coverage plots of H3K9me3 or CBX5 around annotated genes (Ensembl Genes V82) plus/minus 5kb that are in categories of either stably expressed, down regulated or up regulated as defined in differential expression analysis were generated with DeepTools [66] (version 2.5.7).

Author Contributions: Conceptualization, A.K. and J.I.H.; methodology, A.K., S.D., K.H., J.I.H.; software, A.K.; validation, S.D., K.S., K.H., D.P.; formal analysis, A.K., J.I.H.; resources, H.S., M.R., A.B., A.C.M., J.-H.K.; writing-original draft preparation, A.K., J.I.H.; writing—review and editing, J.H.K., A.B., A.C.M., H.S.; visualization, A.K.; supervision, J.I.H.; project administration, J.I.H.; funding acquisition, A.B., J.-H.K., J.I.H. All authors have read and agreed to the published version of the manuscript.

Funding: The authors acknowledge funding by the Duesseldorf School of Oncology (funded by the Comprehensive Cancer Center Düsseldorf/Deutsche Krebshilfe and the Medical Faculty HHU Duesseldorf). JHK receives funding from the European Research Council (ERC) under the European Union's Horizon 2020 research and innovation program (grant agreement No 714226) and is recipient of the St. Baldrick's Robert Arceci Innovation Award. JIH is funded by Deutsche Forschungsgemeinschaft (DFG, HO 5456/3-1) and Martin-Luther University Halle-Wittenberg/University Hospital Halle (Saale). We acknowledge the financial support within the funding program Open Access Publishing by the German Research Foundation (DFG).

Conflicts of Interest: The authors declare no conflict of interest.

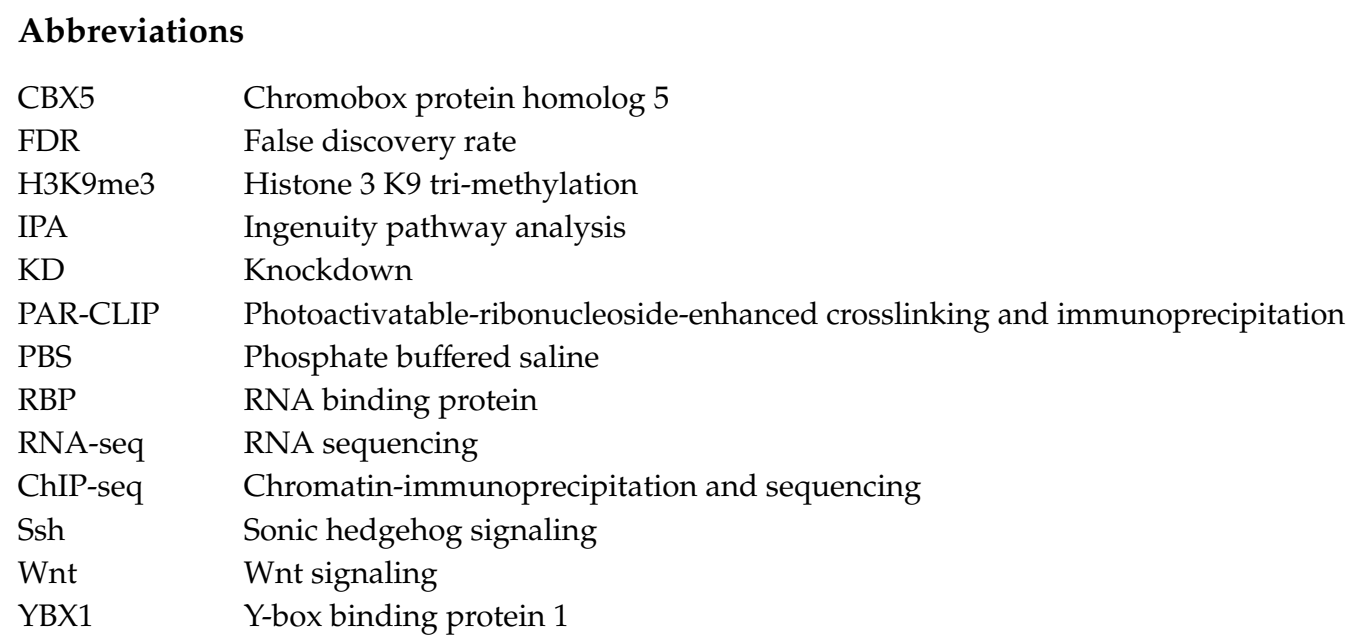




\section{Appendix A}

All sequencing data was deposited at NCBI GEO under the accessions GSE150924 (RNAseq) and GSE150925 (PAR-CLIP). All computational code for the analysis is available upon request from the authors.

a

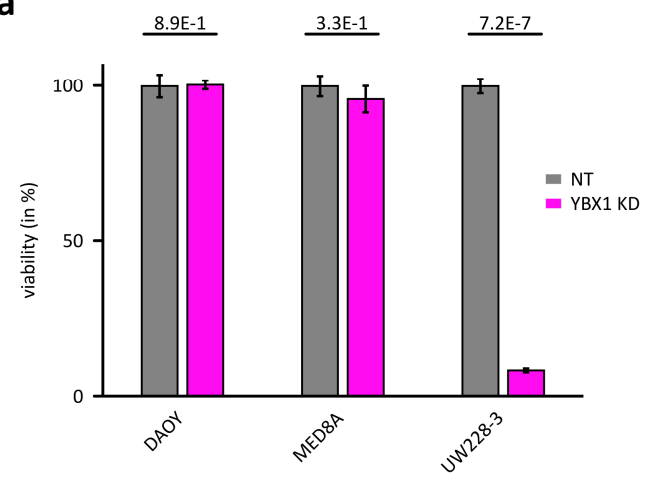

C

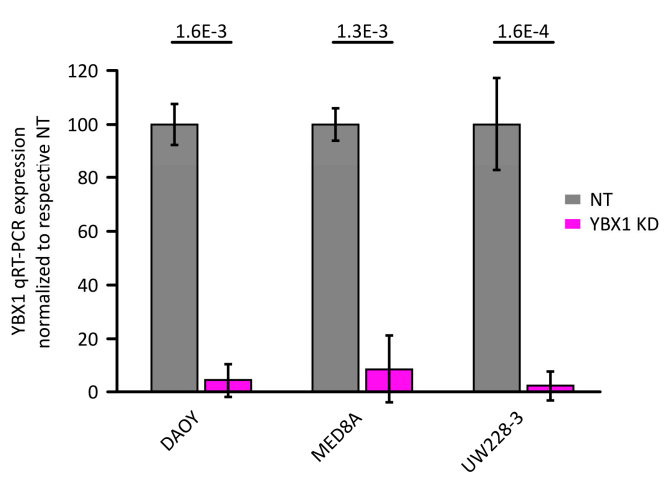

b

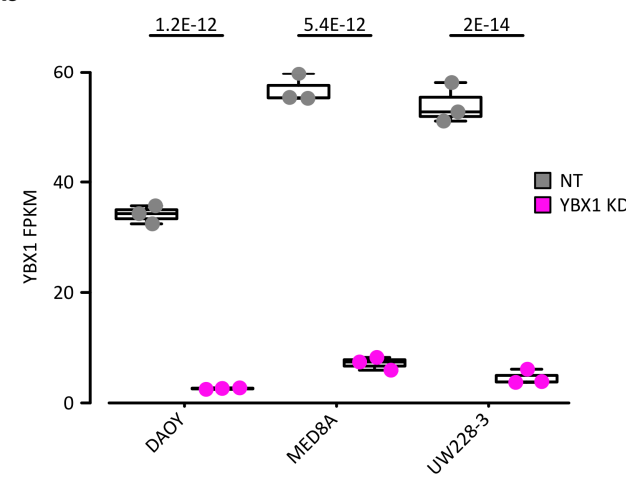

d

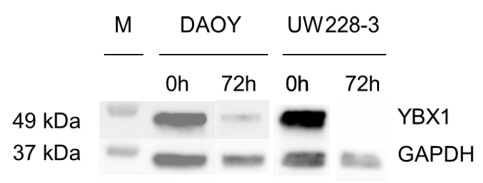

Figure A1. (a) Cell viability of DAOY, MED08A and UW228-3 upon YBX1 KD after $96 \mathrm{~h}$. Significance was calculated using a t-test. (b) YBX1 expression as normalized FPKM taken from RNA-Seq data. Differential expression analysis was performed with edgeR, and FDR values between NT and YBX1 KD are reported. (c) YBX1 expression measured by qRT-PCR each normalized against 18S rRNA, then normalized against the respective cell line NT average. Significance was calculated using an unpaired two-sided t-test. (d) Western blot of YBX1 before and $72 \mathrm{~h}$ after siRNA-mediated knockdown in cell lines DAOY and UW228-3. 
a

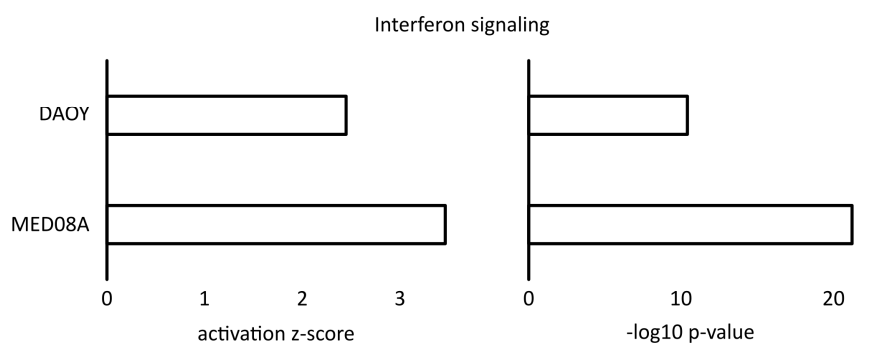

b

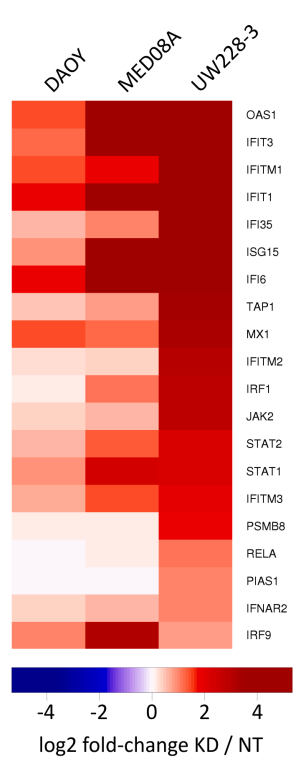

C

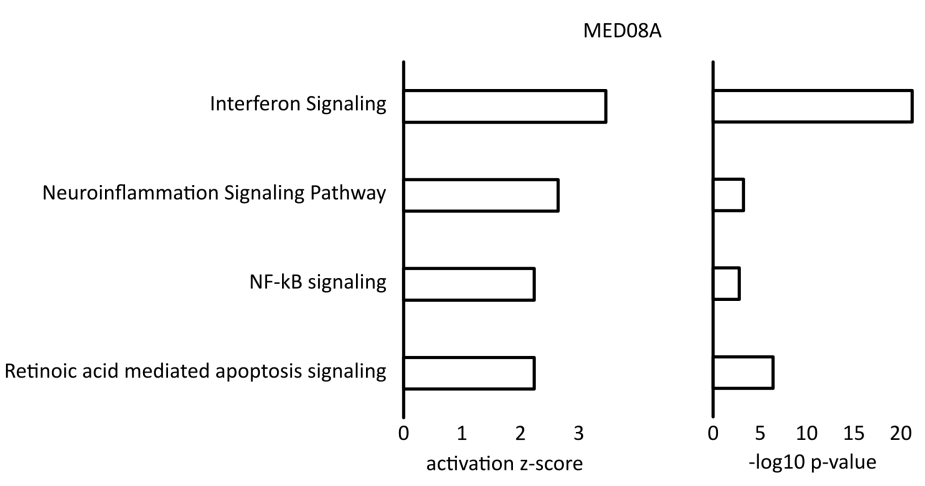

Figure A2. (a) IPA canonical pathway analysis was performed on differentially expressed genes in DAOY and MED08A after YBX1 KD. Activation z-score (left) and - $\log 10$ p-value (right) of "Interferon signaling" are shown. (b) Heatmap of log2 fold-change RNA expression upon YBX1 KD of all genes reported to be differentially expressed in either of the three cell lines upon YBX1 KD that are part of "Interferon Signaling" as reported by IPA canonical pathway analysis. (c) IPA canonical pathway analysis was performed on differentially expressed genes in MED08A after YBX1 KD. Activation z-score (left) and - $\log 10$ p-value (right) of pathways that are also significantly activated in UW228-3 upon YBX1 KD are shown.

a

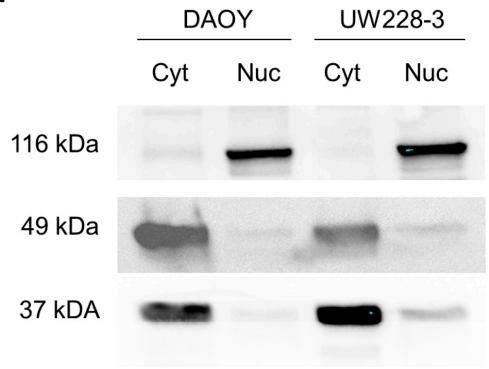

b

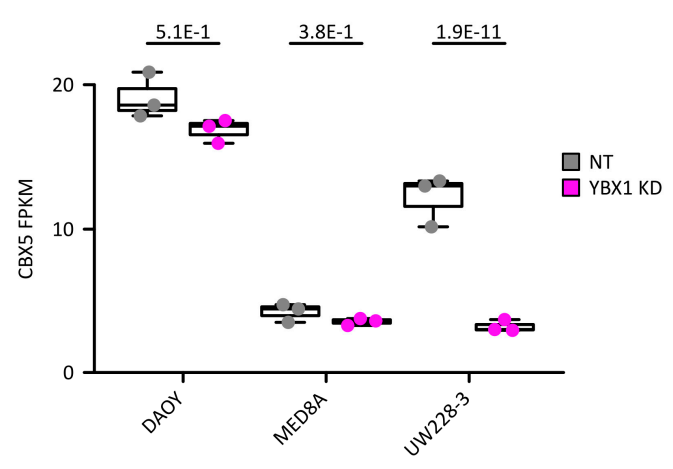

Figure A3. (a) Localization western blot in fractionated cellular protein extract for cytoplasmic fraction (Cyt) and nuclear fraction (Nuc) for nuclear localized protein PARP, cytoplasmic localized protein GAPDH and YBX1 protein in DAOY and UW228-3 cell lines. (b) CBX5 expression as normalized FPKM taken from RNA-Seq data. Differential expression analysis was performed with edgeR, and FDR values between NT and YBX1 KD are reported. 


\section{References}

1. Azzarelli, R.; Simons, B.D.; Philpott, A. The developmental origin of brain tumours: A cellular and molecular framework. Development 2018, 145. [CrossRef] [PubMed]

2. Bautista, F.; Fioravantti, V.; de Rojas, T.; Carceller, F.; Madero, L.; Lassaletta, A.; Moreno, L. Medulloblastoma in children and adolescents: A systematic review of contemporary phase I and II clinical trials and biology update. Cancer Med. 2017, 6, 2606-2624. [CrossRef]

3. Ostrom, Q.T.; Gittleman, H.; Liao, P.; Rouse, C.; Chen, Y.; Dowling, J.; Wolinsky, Y.; Kruchko, C.; Barnholtz-Sloan, J. CBTRUS statistical report: Primary brain and central nervous system tumors diagnosed in the United States in 2007-2011. Neuro-Oncology 2014, 16 (Suppl. 4), iv1-iv63. [CrossRef]

4. Ostrom, Q.T.; Cioffi, G.; Gittleman, H.; Patil, N.; Waite, K.; Kruchko, C.; Barnholtz-Sloan, J.S. CBTRUS Statistical Report: Primary Brain and Other Central Nervous System Tumors Diagnosed in the United States in 2012-2016. Neuro-Oncology 2019, 21, v1-v100. [CrossRef] [PubMed]

5. Cavalli, F.M.G.; Remke, M.; Rampasek, L.; Peacock, J.; Shih, D.J.H.; Luu, B.; Garzia, L.; Torchia, J.; Nor, C.; Morrissy, A.S.; et al. Intertumoral Heterogeneity within Medulloblastoma Subgroups. Cancer Cell 2017, 31, 737-754.e736. [CrossRef]

6. Schuller, U.; Heine, V.M.; Mao, J.; Kho, A.T.; Dillon, A.K.; Han, Y.G.; Huillard, E.; Sun, T.; Ligon, A.H.; Qian, Y.; et al. Acquisition of granule neuron precursor identity is a critical determinant of progenitor cell competence to form Shh-induced medulloblastoma. Cancer Cell 2008, 14, 123-134. [CrossRef]

7. Yang, Z.J.; Ellis, T.; Markant, S.L.; Read, T.A.; Kessler, J.D.; Bourboulas, M.; Schuller, U.; Machold, R.; Fishell, G.; Rowitch, D.H.; et al. Medulloblastoma can be initiated by deletion of Patched in lineage-restricted progenitors or stem cells. Cancer Cell 2008, 14, 135-145. [CrossRef] [PubMed]

8. Phoenix, T.N.; Patmore, D.M.; Boop, S.; Boulos, N.; Jacus, M.O.; Patel, Y.T.; Roussel, M.F.; Finkelstein, D.; Goumnerova, L.; Perreault, S.; et al. Medulloblastoma Genotype Dictates Blood Brain Barrier Phenotype. Cancer Cell 2016, 29, 508-522. [CrossRef] [PubMed]

9. Kawauchi, D.; Robinson, G.; Uziel, T.; Gibson, P.; Rehg, J.; Gao, C.; Finkelstein, D.; Qu, C.; Pounds, S.; Ellison, D.W.; et al. A mouse model of the most aggressive subgroup of human medulloblastoma. Cancer Cell 2012, 21, 168-180. [CrossRef] [PubMed]

10. Pei, Y.; Moore, C.E.; Wang, J.; Tewari, A.K.; Eroshkin, A.; Cho, Y.J.; Witt, H.; Korshunov, A.; Read, T.A.; Sun, J.L.; et al. An animal model of MYC-driven medulloblastoma. Cancer Cell 2012, 21, 155-167. [CrossRef]

11. Wang, J.; Wechsler-Reya, R.J. The role of stem cells and progenitors in the genesis of medulloblastoma. Exp. Neurol. 2014, 260, 69-73. [CrossRef] [PubMed]

12. Lin, C.Y.; Erkek, S.; Tong, Y.; Yin, L.; Federation, A.J.; Zapatka, M.; Haldipur, P.; Kawauchi, D.; Risch, T.; Warnatz, H.J.; et al. Active medulloblastoma enhancers reveal subgroup-specific cellular origins. Nature 2016, 530, 57-62. [CrossRef] [PubMed]

13. Johnston, D.L.; Keene, D.; Strother, D.; Taneva, M.; Lafay-Cousin, L.; Fryer, C.; Scheinemann, K.; Carret, A.S.; Fleming, A.; Afzal, S.; et al. Survival Following Tumor Recurrence in Children With Medulloblastoma. J. Pediatr. Hematol. Oncol. 2018, 40, e159-e163. [CrossRef] [PubMed]

14. Moxon-Emre, I.; Taylor, M.D.; Bouffet, E.; Hardy, K.; Campen, C.J.; Malkin, D.; Hawkins, C.; Laperriere, N.; Ramaswamy, V.; Bartels, U.; et al. Intellectual Outcome in Molecular Subgroups of Medulloblastoma. J. Clin. Oncol. 2016, 34, 4161-4170. [CrossRef]

15. Thomas, A.; Noel, G. Medulloblastoma: Optimizing care with a multidisciplinary approach. J. Multidiscip. Healthc. 2019, 12, 335-347. [CrossRef]

16. Moxon-Emre, I.; Bouffet, E.; Taylor, M.D.; Laperriere, N.; Scantlebury, N.; Law, N.; Spiegler, B.J.; Malkin, D.; Janzen, L.; Mabbott, D. Impact of craniospinal dose, boost volume, and neurologic complications on intellectual outcome in patients with medulloblastoma. J. Clin. Oncol. 2014, 32, 1760-1768. [CrossRef]

17. Ladomery, M.; Sommerville, J. A role for Y-box proteins in cell proliferation. Bioessays 1995, 17, 9-11. [CrossRef]

18. Zou, F.; Tu, R.; Duan, B.; Yang, Z.; Ping, Z.; Song, X.; Chen, S.; Price, A.; Li, H.; Scott, A.; et al. Drosophila YBX1 homolog YPS promotes ovarian germ line stem cell development by preferentially recognizing 5-methylcytosine RNAs. Proc. Natl. Acad. Sci. USA 2020, 117, 3603-3609. [CrossRef] 
19. Ray, D.; Kazan, H.; Chan, E.T.; Castillo, L.P.; Chaudhry, S.; Talukder, S.; Blencowe, B.J.; Morris, Q.; Hughes, T.R. Rapid and systematic analysis of the RNA recognition specificities of RNA-binding proteins. Nat. Biotechnol. 2009, 27, 667-670. [CrossRef]

20. Wei, W.-J.; Mu, S.-R.; Heiner, M.; Fu, X.; Cao, L.-J.; Gong, X.-F.; Bindereif, A.; Hui, J. YB-1 binds to CAUC motifs and stimulates exon inclusion by enhancing the recruitment of U2AF to weak polypyrimidine tracts. Nucleic Acids Res. 2012, 40, 8622-8636. [CrossRef]

21. Wu, S.-L.; Fu, X.; Huang, J.; Jia, T.-T.; Zong, F.-Y.; Mu, S.-R.; Zhu, H.; Yan, Y.; Qiu, S.; Wu, Q. Genome-wide analysis of YB-1-RNA interactions reveals a novel role of YB-1 in miRNA processing in glioblastoma multiforme. Nucleic Acids Res. 2015, 43, 8516-8528. [CrossRef]

22. Goodarzi, H.; Liu, X.; Nguyen, H.C.; Zhang, S.; Fish, L.; Tavazoie, S.F. Endogenous tRNA-derived fragments suppress breast cancer progression via YBX1 displacement. Cell 2015, 161, 790-802. [CrossRef] [PubMed]

23. Lu, Z.H.; Books, J.T.; Ley, T.J. YB-1 is important for late-stage embryonic development, optimal cellular stress responses, and the prevention of premature senescence. Mol. Cell. Biol. 2005, 25, 4625-4637. [CrossRef] [PubMed]

24. Evdokimova, V.; Ruzanov, P.; Imataka, H.; Raught, B.; Svitkin, Y.; Ovchinnikov, L.P.; Sonenberg, N. The major mRNA-associated protein YB-1 is a potent $5^{\prime}$ cap-dependent mRNA stabilizer. EMBO J. 2001, 20, 5491-5502. [CrossRef] [PubMed]

25. Nekrasov, M.P.; Ivshina, M.P.; Chernov, K.G.; Kovrigina, E.A.; Evdokimova, V.M.; Thomas, A.A.; Hershey, J.W.; Ovchinnikov, L.P. The mRNA-binding protein YB-1 (p50) prevents association of the eukaryotic initiation factor eIF4G with mRNA and inhibits protein synthesis at the initiation stage. J. Biol. Chem. 2003, 278, 13936-13943. [CrossRef] [PubMed]

26. Coles, L.S.; Bartley, M.A.; Bert, A.; Hunter, J.; Polyak, S.; Diamond, P.; Vadas, M.A.; Goodall, G.J. A multi-protein complex containing cold shock domain (Y-box) and polypyrimidine tract binding proteins forms on the vascular endothelial growth factor mRNA: Potential role in mRNA stabilization. Eur. J. Biochem. 2004, 271, 648-660. [CrossRef]

27. Dutertre, M.; Sanchez, G.; De Cian, M.-C.; Barbier, J.; Dardenne, E.; Gratadou, L.; Dujardin, G.; Le Jossic-Corcos, C.; Corcos, L.; Auboeuf, D. Cotranscriptional exon skipping in the genotoxic stress response. Nat. Struct. Mol. Biol. 2010, 17, 1358. [CrossRef] [PubMed]

28. Skalweit, A.; Doller, A.; Huth, A.; Kähne, T.; Persson, P.B.; Thiele, B.-J. Posttranscriptional control of renin synthesis: Identification of proteins interacting with renin mRNA 3'-untranslated region. Circ. Res. 2003, 92, 419-427. [CrossRef]

29. Lyabin, D.N.; Eliseeva, I.A.; Ovchinnikov, L.P. YB-1 protein: Functions and regulation. Wiley Interdiscip. Rev. RNA 2014, 5, 95-110. [CrossRef]

30. Faury, D.; Nantel, A.; Dunn, S.E.; Guiot, M.-C.; Haque, T.; Hauser, P.; Garami, M.; Bognár, L.; Hanzély, Z.; Liberski, P.P. Molecular profiling identifies prognostic subgroups of pediatric glioblastoma and shows increased YB-1 expression in tumors. J. Clin. Oncol. 2007, 25, 1196-1208. [CrossRef]

31. Chatterjee, M.; Rancso, C.; Stühmer, T.; Eckstein, N.; Andrulis, M.; Gerecke, C.; Lorentz, H.; Royer, H.-D.; Bargou, R.C. The Y-box binding protein YB-1 is associated with progressive disease and mediates survival and drug resistance in multiple myeloma. Blood 2008, 111, 3714-3722. [CrossRef] [PubMed]

32. Fujii, T.; Kawahara, A.; Basaki, Y.; Hattori, S.; Nakashima, K.; Nakano, K.; Shirouzu, K.; Kohno, K.; Yanagawa, T.; Yamana, H. Expression of HER2 and estrogen receptor $\alpha$ depends upon nuclear localization of Y-box binding protein-1 in human breast cancers. Cancer Res. 2008, 68, 1504-1512. [CrossRef] [PubMed]

33. Mantwill, K.; Naumann, U.; Seznec, J.; Girbinger, V.; Lage, H.; Surowiak, P.; Beier, D.; Mittelbronn, M.; Schlegel, J.; Holm, P.S. YB-1 dependent oncolytic adenovirus efficiently inhibits tumor growth of glioma cancer stem like cells. J. Transl. Med. 2013, 11, 216. [CrossRef] [PubMed]

34. Stratford, A.L.; Habibi, G.; Astanehe, A.; Jiang, H.; Hu, K.; Park, E.; Shadeo, A.; Buys, T.P.; Lam, W.; Pugh, T. Epidermal growth factor receptor (EGFR) is transcriptionally induced by the Y-box binding protein-1 (YB-1) and can be inhibited with Iressa in basal-like breast cancer, providing a potential target for therapy. Breast Cancer Res. 2007, 9, R61. [CrossRef] [PubMed]

35. Remke, M.; Hielscher, T.; Korshunov, A.; Northcott, P.A.; Bender, S.; Kool, M.; Westermann, F.; Benner, A.; Cin, H.; Ryzhova, M. FSTL5 is a marker of poor prognosis in non-WNT/non-SHH medulloblastoma. J. Clin. Oncol. 2011, 2011, 2036-2798. [CrossRef] 
36. Liao, J.-Y.; Yang, B.; Zhang, Y.-C.; Wang, X.-J.; Ye, Y.; Peng, J.-W.; Yang, Z.-Z.; He, J.-H.; Zhang, Y.; Hu, K. EuRBPDB: A comprehensive resource for annotation, functional and oncological investigation of eukaryotic RNA binding proteins (RBPs). Nucleic Acids Res. 2020, 48, D307-D313. [CrossRef]

37. Behan, F.M.; Iorio, F.; Picco, G.; Goncalves, E.; Beaver, C.M.; Migliardi, G.; Santos, R.; Rao, Y.; Sassi, F.; Pinnelli, M.; et al. Prioritization of cancer therapeutic targets using CRISPR-Cas9 screens. Nature 2019, 568, 511-516. [CrossRef]

38. Jacobsen, P.F.; Jenkyn, D.J.; Papadimitriou, J.M. Establishment of a human medulloblastoma cell line and its heterotransplantation into nude mice. J. Neuropathol. Exp. Neurol. 1985, 44, 472-485. [CrossRef]

39. Keles, G.E.; Berger, M.S.; Srinivasan, J.; Kolstoe, D.D.; Bobola, M.S.; Silber, J.R. Establishment and characterization of four human medulloblastoma-derived cell lines. Oncol. Res. 1995, 7, 493-503.

40. Bazan, N.G.; Halabi, A.; Ertel, M.; Petasis, N.A. Neuroinflammation. In Basic Neurochemistry; Elsevier: Amsterdam, The Netherlands, 2012; pp. 610-620.

41. Bannister, A.J.; Zegerman, P.; Partridge, J.F.; Miska, E.A.; Thomas, J.O.; Allshire, R.C.; Kouzarides, T. Selective recognition of methylated lysine 9 on histone H3 by the HP1 chromo domain. Nature 2001, 410, 120-124. [CrossRef]

42. Kwon, S.H.; Workman, J.L. The heterochromatin protein 1 (HP1) family: Put away a bias toward HP1. Mol. Cells (Springer Sci. Bus. Media BV) 2008, 26, 217-227.

43. Dey, A.; Robitaille, M.; Remke, M.; Maier, C.; Malhotra, A.; Gregorieff, A.; Wrana, J.L.; Taylor, M.D.; Angers, S.; Kenney, A.M. YB-1 is elevated in medulloblastoma and drives proliferation in Sonic hedgehog-dependent cerebellar granule neuron progenitor cells and medulloblastoma cells. Oncogene 2016, 35, 4256-4268. [CrossRef] [PubMed]

44. Dai, J.; Li, Q.; Bing, Z.; Zhang, Y.; Niu, L.; Yin, H.; Yuan, G.; Pan, Y. Comprehensive analysis of a microRNA expression profile in pediatric medulloblastoma. Mol. Med. Rep. 2017, 15, 4109-4115. [CrossRef] [PubMed]

45. Kuwano, M.; Shibata, T.; Watari, K.; Ono, M. Oncogenic Y-box binding protein-1 as an effective therapeutic target in drug-resistant cancer. Cancer Sci. 2019, 110, 1536-1543. [CrossRef]

46. Di, C.; Liao, S.; Adamson, D.C.; Parrett, T.J.; Broderick, D.K.; Shi, Q.; Lengauer, C.; Cummins, J.M.; Velculescu, V.E.; Fults, D.W. Identification of OTX2 as a medulloblastoma oncogene whose product can be targeted by all-trans retinoic acid. Cancer Res. 2005, 65, 919-924. [PubMed]

47. Chang, Q.; Chen, Z.; You, J.; McNutt, M.A.; Zhang, T.; Han, Z.; Zhang, X.; Gong, E.; Gu, J. All-trans-retinoic acid induces cell growth arrest in a human medulloblastoma cell line. J. Neuro-Oncol. 2007, 84, $263-267$. [CrossRef]

48. Hallahan, A.R.; Pritchard, J.I.; Chandraratna, R.A.; Ellenbogen, R.G.; Geyer, J.R.; Overland, R.P.; Strand, A.D.; Tapscott, S.J.; Olson, J.M. BMP-2 mediates retinoid-induced apoptosis in medulloblastoma cells through a paracrine effect. Nat. Med. 2003, 9, 1033-1038. [CrossRef]

49. Gumireddy, K.; Sutton, L.N.; Phillips, P.C.; Reddy, C.D. All-trans-Retinoic Acid-induced Apoptosis in Human Medulloblastoma Activation of Caspase-3/Poly (ADP-ribose) Polymerase 1 Pathway. Clin. Cancer Res. 2003, 9, 4052-4059.

50. Liu, J.; Guo, L.; Jun-Wei, L.; Liu, N.; Li, H. All-trans retinoic acid modulates fas expression and enhances chemosensitivity of human medulloblastoma cells. Int. J. Mol. Med. 2000, 5, 145-154. [CrossRef]

51. Tao, Z.; Ruan, H.; Sun, L.; Kuang, D.; Song, Y.; Wang, Q.; Wang, T.; Hao, Y.; Chen, K. Targeting the YB-1/PD-L1 Axis to Enhance Chemotherapy and Antitumor Immunity. Cancer Immunol. Res. 2019, 7, 1135-1147. [CrossRef]

52. Ivanov, D.P.; Coyle, B.; Walker, D.A.; Grabowska, A.M. In vitro models of medulloblastoma: Choosing the right tool for the job. J. Biotechnol. 2016, 236, 10-25. [CrossRef] [PubMed]

53. Saksouk, N.; Hajdari, S.; Perez, Y.; Pratlong, M.; Barrachina, C.; Graber, C.; Grégoire, D.; Zavoriti, A.; Sarrazin, A.; Pirot, N. The mouse HP1 proteins are essential for preventing liver tumorigenesis. Oncogene 2020, 39, 2676-2691. [CrossRef]

54. Higashijima, Y.; Matsui, Y.; Shimamura, T.; Nakaki, R.; Nagai, N.; Tsutsumi, S.; Abe, Y.; Link, V.M.; Osaka, M.; Yoshida, M. Coordinated demethylation of $\mathrm{H} 3 \mathrm{~K} 9$ and $\mathrm{H} 3 \mathrm{~K} 27$ is required for rapid inflammatory responses of endothelial cells. EMBO J. 2020. [CrossRef]

55. Khan, M.I.; Adhami, V.M.; Lall, R.K.; Sechi, M.; Joshi, D.C.; Haidar, O.M.; Syed, D.N.; Siddiqui, I.A.; Chiu, S.Y.; Mukhtar, H. YB-1 expression promotes epithelial-to-mesenchymal transition in prostate cancer that is inhibited by a small molecule fisetin. Oncotarget 2014, 5, 2462-2474. [CrossRef] 
56. Schneider, C.A.; Rasband, W.S.; Eliceiri, K.W. NIH Image to ImageJ: 25 years of image analysis. Nat. Methods 2012, 9, 671-675. [CrossRef] [PubMed]

57. Hannus, M.; Beitzinger, M.; Engelmann, J.C.; Weickert, M.-T.; Spang, R.; Hannus, S.; Meister, G. siPools: Highly complex but accurately defined siRNA pools eliminate off-target effects. Nucleic Acids Res. 2014, 42, 8049-8061. [CrossRef]

58. Spitzer, J.; Hafner, M.; Landthaler, M.; Ascano, M.; Farazi, T.; Wardle, G.; Nusbaum, J.; Khorshid, M.; Burger, L.; Zavolan, M.; et al. PAR-CLIP (Photoactivatable Ribonucleoside-Enhanced Crosslinking and Immunoprecipitation): A step-by-step protocol to the transcriptome-wide identification of binding sites of RNA-binding proteins. Methods Enzym. 2014, 539, 113-161. [CrossRef]

59. Dobin, A.; Davis, C.A.; Schlesinger, F.; Drenkow, J.; Zaleski, C.; Jha, S.; Batut, P.; Chaisson, M.; Gingeras, T.R. STAR: Ultrafast universal RNA-seq aligner. Bioinformatics 2013, 29, 15-21. [CrossRef] [PubMed]

60. Robinson, M.D.; McCarthy, D.J.; Smyth, G.K. edgeR: A Bioconductor package for differential expression analysis of digital gene expression data. Bioinformatics 2010, 26, 139-140. [CrossRef] [PubMed]

61. Martin, M. Cutadapt removes adapter sequences from high-throughput sequencing reads. Embnet. J. 2011, 17, 10-12. [CrossRef]

62. Kloetgen, A.; Borkhardt, A.; Hoell, J.I.; McHardy, A.C. The PARA-suite: PAR-CLIP specific sequence read simulation and processing. PeerJ 2016, 4, e2619. [CrossRef] [PubMed]

63. Heinz, S.; Benner, C.; Spann, N.; Bertolino, E.; Lin, Y.C.; Laslo, P.; Cheng, J.X.; Murre, C.; Singh, H.; Glass, C.K. Simple combinations of lineage-determining transcription factors prime cis-regulatory elements required for macrophage and B cell identities. Mol. Cell 2010, 38, 576-589. [CrossRef]

64. Bailey, T.L.; Johnson, J.; Grant, C.E.; Noble, W.S. The MEME suite. Nucleic Acids Res. 2015, 43, W39-W49. [CrossRef] [PubMed]

65. Consortium, E.P. An integrated encyclopedia of DNA elements in the human genome. Nature 2012, 489, 57-74. [CrossRef] [PubMed]

66. Ramírez, F.; Dündar, F.; Diehl, S.; Grüning, B.A.; Manke, T. deepTools: A flexible platform for exploring deep-sequencing data. Nucleic Acids Res. 2014, 42, W187-W191. [CrossRef] [PubMed]

(C) 2020 by the authors. Licensee MDPI, Basel, Switzerland. This article is an open access article distributed under the terms and conditions of the Creative Commons Attribution (CC BY) license (http://creativecommons.org/licenses/by/4.0/). 